\title{
An Overview on Severe Combined Immunodeficiency Disorders
}

\author{
Aisha Jamal*, Tahir Shamsi \\ National Institute of Blood Disease \& Bone Marrow Transplantation, Karachi, Pakistan.
}

\section{INTRODUCTION}

Severe Combined Immunodeficiency Disorders (SCID) are rare life-threatening inherited conditions. They are characterised by the absence or non-functional immune system $[1,2]$. As a result, affected children are unable to fight infections. Living in normal environment usually proves fatal for affected children. They get very sick with recurrent attacks of bacterial, viral and fungal infections and do not survive beyond first year of life. There are many genetic mutations responsible for different types of SCID. T-lymphocytes, B-lymphocytes and natural killer cells (NK-cells) can all be affected; two common types are the X-linked and the Adenosine Deaminase Deficiency (ADA deficiency). Affected kids develop symptoms usually within the first few months of life. Commonly affected body systems are; lungs, meninges, blood stream, skin, gut and liver. In the absence of efficient immune system, causative organisms do not easily respond to anti-microbial agents. Recurrent episodes of serious and life-threatening infections like pneumonia, meningitis, septicaemia, chronic skin infections, diarrhoea, and hepatitis result in death within first year of life [1].

Following are the important sub-types of SCID [2].

\section{T-B+ SCID}

The other variety of SCID includes T-B+ SCID where T-cells are missing but $\mathrm{B}$ cells can be present even in increased numbers. However, the produced B cells are functionally defective in X-linked SCID. It accounts for $40-50 \%$ of all cases [3]. The defect lies in IL-2 receptor $\gamma$-chain mutations which lead to a very low number of T-cells and NK-cells in circulation. The mutation lies in JAK-3 gene. It is an autosomal recessive disorder. Other SCID includes MHC Class I Deficiency, MHC class II Deficiency and others.

Recurrent recalcitrant infections raise the suspicion of a diagnosis of SCID [4]. In countries where BCG vaccination is given immediately after birth, abscess at the injection site and lymphadenopathy in the draining group is not an uncommon first presentation in SCID children. A family history of an affected sibling, or a cousin, detailed medical history, and physical examination of the child are collectively highly suggestive of the underlying SCID diagnosis. Complete blood

*Address correspondence to this author at the National Institute of Blood Disease \& Bone Marrow Transplantation, Karachi, Pakistan.

E-mail: draishajamal@outlook.com count may reveal low or absent absolute lymphocyte count. At birth, the lymphocyte count may be normal or low but in next few weeks to few months of life, lymphocyte count continue to fall. Lymphocyte subset analysis using flowcytometer is a very useful and sensitive method to diagnose SCID [5]. Immunoglobulin levels (IgM, IgG, $\operatorname{Ig} A$, and $\operatorname{IgE}$ ) have to be interpreted with caution during first 3-4 months of life as the infants usually have spuriously normal levels due to the presence of maternal IgG in the serum.

Once diagnosed, treatment of SCID requires involvement of specialist centre capable of providing comprehensive care to affected children including bone marrow transplantation $[6$, 7]. Initially, good supportive care to counter infections should be provided and a search for HLA matched donor for bone marrow transplant should be started simultaneously.

This requires HLA typing of affected child and siblings and / or parents. A full HLA match donor is preferable but a haplo-identical parental donor or a sibling is a reasonable alternative. Bone marrow transplantation is the only curative treatment for most types.

When a full HLA matched family donor is identified, bone marrow transplant can be performed without any prior conditioning chemotherapy to the affected kid. But this is hardly the case in many patients. Usually a haplo-identical donor is available requiring some immunotherapy and / or myeloablative conditioning therapy. Graft versus host disease (GvHD) prophylaxis may not be given in case of a full match transplant but in other settings, this prophylaxis is given to prevent GvHD and graft loss. Gene therapy also offers a cure in ADA deficiency and Chediak-Higashi syndrome. But gene therapy is available in only few centres across the globe [7].

\section{BONE MARROW TRANSPLANT}

Bone Marrow Transplant involves harvesting of haematopoietic stem cells from the bone marrow of the donor. In some situations, these cells can be mobilised by using granulocyte-colony stimulating factor (G-CSF) and stem cells are collected from the peripheral blood of the donor. Once harvested, these cells are infused directly to the patient like a blood transfusion. The adequacy of the dose of stem cells is found by counting the number of cells in the harvested product using a flowcytometer. A total dose of more than 4 million cells (expressing CD-34 antigens on their surface) per kilogram body weight of the recipient (patient) is considered 
adequate. The neutrophils and platelet engraftment of donor origin occurs within first 14-21 days of transplant. While the missing lymphocytes starts to appear in the patient's blood stream after day 28-42 of transplant. During this period, the child is kept in BMT unit in protective isolation and given all the prophylactic measures to prevent any infection. Breast feeding is recommended during this period as it is a good source of maternal antibodies.

Other therapeutic options like ADA enzyme therapy in ADA deficient kids and intravenous immunoglobulin in those kids with absent B-cells are adjunct approaches till a definitive treatment is given.

An important consideration is to counsel the couple about the availability of prenatal diagnosis in future pregnancies [5]. This is available in many countries including Pakistan. In affected families, carrier detection is very important along with genetic counselling regarding mode of inheritance of this disease and chances of transmission to the offsprings. In our country, $60-70 \%$ marriages take place within the extended family, bradri or tribe. This makes it very important to provide such counselling to the family members so that the birth of affected children can be prevented. Actual incidence of SCID in Pakistan, like other developing countries, is not known [8, 9]. In USA, the reported incidence is 1 in 1200 is reported [10].

Majority of these patients remain undiagnosed. Only a handful cases are identified each year. By the time the diagnosis is made, they are already in a moribund state. Only a few patients reach to a treatment centre that either already have a history of an affected sibling or parents bring the neonate to a paediatrician/neonatologist for diagnostic workup. An early and timely referral to a transplant centre is extremely important; number of infective episodes prior to BMT is inversely proportional to the chances of success. BMT in first three months of life where there was no or one episode of infection has an overall more than $90 \%$ chance of a cure. While each subsequent episode of severe infection reduces the success rate by $10 \%$.

\section{CONCLUSION}

In conclusion, SCID is suspected in neonate where there is a history of an affected sibling or where there is a history of recurrent infections requiring hospitalisation. Early diagnosis and timely referral to a specialist centre is life saving. BMT is curative when performed early in life. A focus on prevention of this disorder in the affected couple and identification of carriers of SCID is of utmost importance for prevention.

\section{CONFLICT OF INTEREST}

Declared none.

\section{ACKNOWLEDGEMENTS}

Declared none.

\section{REFERENCES}

[1] Ochs HD, Hagin D. Primary immunodeficiency disorders: General classification, new molecular insights, and practical approach to diagnosis and treatment. Ann Allergy Asthma Immunol 2014; 112: 489-95. DOI: 10.1016/j.anai.2014.04.007

[2] Buckley RH, Schiff RI, Schiff SE, et al. Human severe combined immunodeficiency: Genetic phenotypic, and functional diversity in one hundred eight infants. J Pediatr 1997; 130: 378-87. DOI: 10.1016/S0022-3476(97)70199-9

[3] Madkaikar M, Italia K, Gupta M, et al. Molecular characterization of leukocyte adhesion deficiency-I in Indian patients: Identification of 9 novel mutations. Blood Cells Mol Dis 2015; 54: 217-23. DOI: 10.1016/j.bcmd.2015.01.012

[4] Borte S, von Döbeln U, Hammarström L. Guidelines for newborn screening of primary immunodeficiency diseases. Curr Opin Hematol 2013; 20: 48-54.

DOI: 10.1097/MOH.0b013e32835a9130

[5] Mishra A, Gupta M, Dalvi A, Ghosh K, Madkaikar M. Rapid flow cytometric prenatal diagnosis of primary immunodeficiency (PID) disorders. J Clin Immunol 2014; 34: 316-22. DOI: 10.1007/s10875-014-9993-7

[6] Gaspar HB, Qasim W, Davies EG, Rao K, Amrolia PJ, Veys P. How I treat severe combine immunodeficiency. Blood. 2013; 122: 3749-58. DOI: 10.1182/blood-2013-02-380105

[7] European Society for Immunodeficiencies. Bone Marrow Transplantation \& Gene Therapy. EBMT/ ESID guidelines for haematopoietic stem cell transplantation for PI. Available at: https://esid.org/layout/set/print/Working-Parties/Inborn-Error s-Working-Party-IEWP/Resources/UPDATED!-EBMT-ESID -GUIDELINES-FOR-HAEMATOPOIETIC-STEM-CELL-T RANSPLANTATION-FOR-PI [Accessed August 2018].

[8] Gupta S, Madkaikar M, Singh S, Sehgal S. Primary immunodeficiencies in India: A perspective. Ann NY Acad Sci 2012; 1250: 73-9.

DOI: $10.1111 /$ j.1749-6632.2011.06353.x

[9] Suliaman F, Al-Ghonaium A, Harfi H. High incidence of severe combined immune deficiency in the Eastern Province of Saudi Arabia. Pediatr Asthma Allergy Immunol 2006; 19: 14-8. DOI: $10.1089 /$ pai.2006.19.14

[10] Boyle JM, Buckley RH. Population prevalence of diagnosed primary immunodeficiency diseases in the United States. J Clin Immunol 2007; 27: 497-502.

DOI: $10.1007 / \mathrm{s} 10875-007-9103-1$ 